\title{
NUCLEOTIDE THERAPY IN AGRANULOCYTOSIS
}

\author{
BY PAUL REZNIKOFF
}

(From the Department of Medicine, Cornell University Medical College and the Second Medical (Cornell) Division, Bellevue Hospital, New York City)

(Received for publication June 27, 1930)

In recent years many reports (1 through 14) have appeared of a condition first described by Schwarz (15) and called by Schultz (16) agranulocytic angina. This is characterized by fever, by intense prostration, by a sore throat, sometimes almost gangrenous in appearance, by large purpuric areas on the body which frequently become necrotic, and by a marked leukopenia, especially of the polymorphonuclear cells. The course is usually acute and the mortality is so high that when a patient recovers it is sufficiently significant to merit a report.

No definite causative agent has as yet been found. Moreover, some skepticism exists as to whether agranulocytic angina is a clinical entity (14). Blumer (17) describes agranulocytosis, the outstanding feature of the condition, in other infectious diseases and Wilson (18), and McCord (19) point out its occurrence in arsenic and benzene poisoning. On the Second Medical Division of Bellevue Hospital a considerable depression of the granulocytes was found in some of the patients with pneumonia and tuberculosis.

Roberts and Kracke (20) believe that there is a definite disease entity known as agranulocytosis and base their opinion on a case which showed a marked marrow deficiency before any other symptom or sign occurred. Their conclusion does not necessarily follow because blood cell response usually precedes other symptoms and signs in most conditions. For instance a marked "shift to the left" of the polynuclears in an infectious condition is usually present from 24 to 48 hours before other symptoms and signs are seen (21). The present evidence makes it probable that agranulocytosis is due to a depression of the production of granulocytes or of their delivery into the circulation because of an 
inherent failure of the particular organism in the course of a toxemia rather than because of any definite toxic agent.

Agranulocytosis has been treated principally by transfusions and roentgen therapy. Since in this condition the other blood elements are usually not affected (22), this disease should lend itself to treatment by the stimulation of the polymorphonuclear elements by nucleotides such as adenine sulfate and guanine hydrochloride. Doan, Zerfas, Warren and Ames (23) and Reznikoff (24) have shown that the nucleotides, when given intravenously, cause a marked increase in the polymorphonuclear cells in rabbits without any effect on the temperature or on blood cells other than the granulocytes.

Guanine or 2-amino-6-oxypurine has the empirical formula $\mathrm{C}_{5} \mathrm{H}_{5} \mathrm{~N}_{5} \mathrm{O}$ and has the structural formula<smiles>[H][Y]Nc1nc2ncc([2H])[nH]c-2n1</smiles>

Adenine has the empirical formula $\mathrm{C}_{5} \mathrm{H}_{5} \mathrm{~N}_{5}$ with the structural formula<smiles>Nc1ncnc2nc[nH]c12</smiles>

These two materials, obtained from the Eastman Kodak Company, are both prepared by the hydrolysis of yeast nucleic acid. This is hydrolyzed with 10 per cent sulfuric acid. The solution is made alkaline, which causes a precipitation of the crude guanine. The adenine remains in the alkaline solution. The crude guanine is dissolved in hot hydrochloric acid. Upon cooling the crystals of guanine hydrochloride precipitate out. The alkaline filtrate containing the adenine is made just acid. To this solution copper sulfate is added which causes the formation of an insoluble adenine cuprous compound. This compound is broken up with hydrogen sulfide which results in the precipitation of the copper. The filtrate, after the removal of the cuprous sulfide, is evaporated to dryness. This residue is dissolved in hot sulfuric acid and upon cooling the adenine sulfate crystallizes out. 
In the patients to be described $0.5 \mathrm{gram}$ of the nucleotide was given intravenously in about $20 \mathrm{cc}$. of physiological saline. The nucleotide was boiled in the saline. Certain preparations of nucleotides are insoluble in saline. In such cases 10 per cent $\mathrm{HCl}$ was added drop by drop during the boiling until a homogeneous suspension was formed. If introduced into the vein slowly a little discomfort was felt with the administration of the acidulated product and none with the soluble nucleotide.

The following results were obtained with the patients suffering from agranulocytic angina.

Patient I. ${ }^{1}$ Young male physician at the City Hospital, New York City, developed a sore throat, headache, chills, cough, was nauseated and vomited, became delirious and showed a large slough on his buttock. The other salient features of his condition are given in table 1 .

The patient's throat cleared up completely. He was extremely weak and the slough on his buttock healed slowly. He was discharged in good condition to a convalescent home on March 19, 1928. In June, 1929 he had an attack of acute tonsillitis at home. His temperature was 101-102 for about 2 days and his physician reported a normal blood count. On June 25th his count was 7400 white blood cells, 65 per cent polymorphonuclears. His tonsils were removed in July, 1929 with no untoward results. He was in perfect health until May, 1930 when he developed some apical abscesses of two teeth. Vincent's spirillum was recovered and upon extraction of the teeth in June another attack of agranulocytosis was precipitated. The details of this attack are not available but the essential features are the following: After two transfusions of $500 \mathrm{cc}$. the patient's condition became worse and the blood count decreased to 500 white blood cells, no polymorphonuclears being seen in the entire slide. His physician, Dr. Jacobs, began injection of adenine sulphate, giving 0.5 gram in $25 \mathrm{cc}$. of saline very day. In addition he continued daily transfusions. Six hours after the injection of the first dose of adenine sulphate, the white blood cell count began to rise, polymorphonuclears appeared and the patient's general condition began to improve. He was discharged in a month and has been in good health since.

Patient II. ${ }^{2}$ A middle aged woman had an unhealed cyst at the lower end of her spine. During her stay in the hospital a blood count showed 3400 white blood cells and no polymorphonuclears were seen in at least 300 white cells. Generalized ultraviolet treatment was instituted and she improved. One month later her total white blood cell count was 7000 of which 51 per cent were polymorphonu-

\footnotetext{
${ }^{1}$ I am indebted to Drs. Jacobs, Lisa, Coyne and the other members of the City Hospital Staff for permission to report this case.

${ }^{2}$ I wish to thank Dr. Herbert Bergamini and the staff of the Reconstruction Hospital for their help and permission to quote this case.
} 


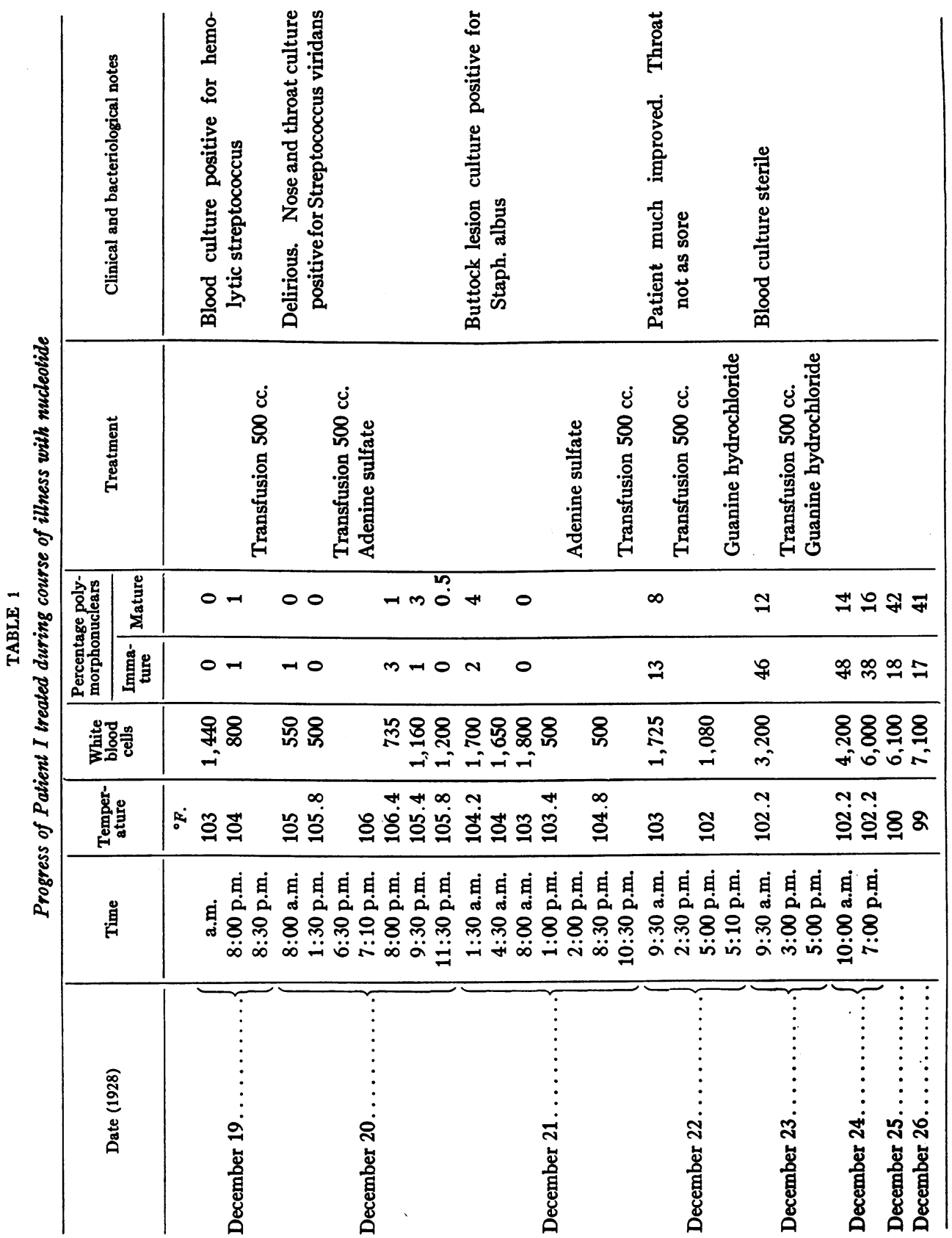


clears. One month after this she had an accident and was admitted to the ward with a fractured nose, sore throat, fever and a marked agranulocytosis. The salient features of her illness are given in table 2.

The patient refused further treatment and was subsequently discharged with a normal count. No throat culture was taken. The subsequent history of the patient was that she improved in general health and her physician put her on

TABLE 2

Progress of Patient II treated during course of illness with nucleotide

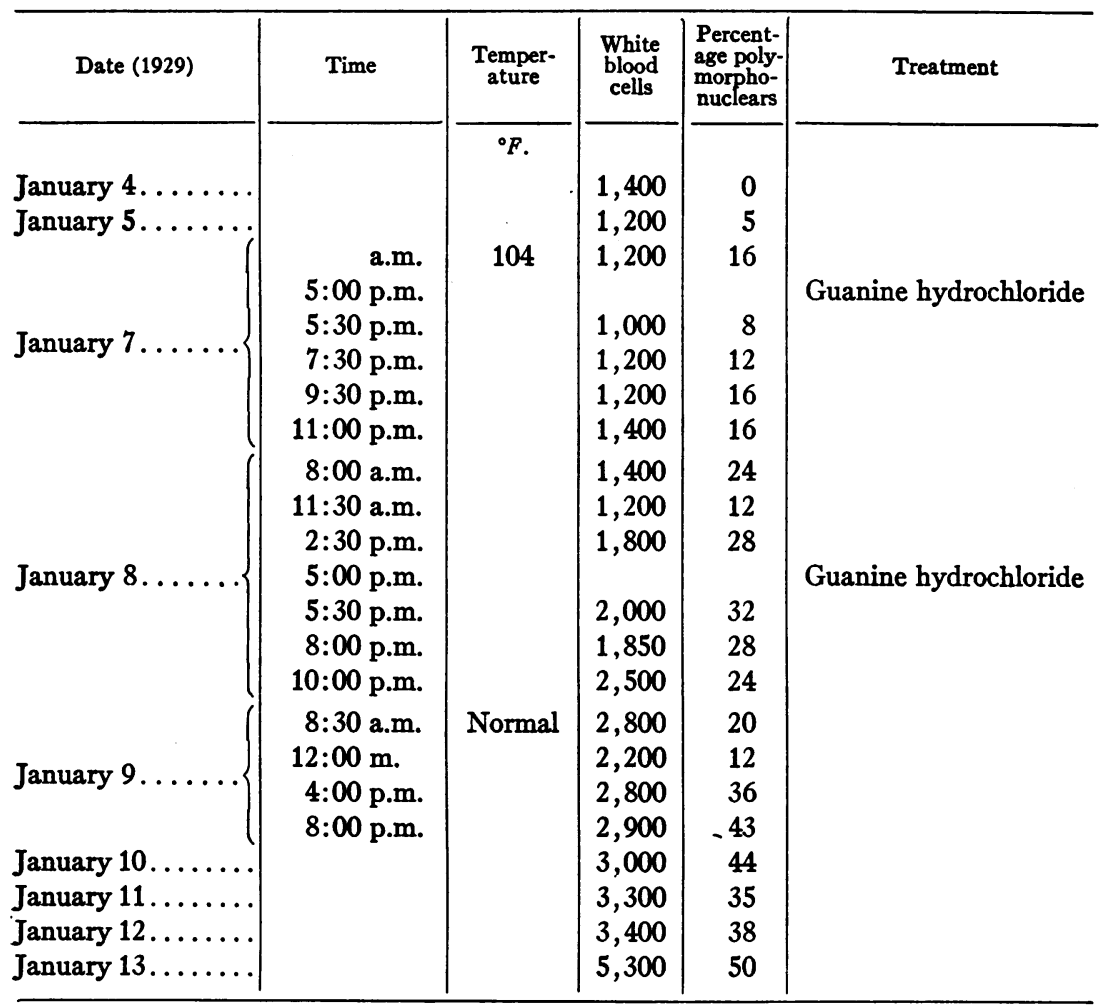

Armour's Extract of Spleen. Her counts reported by her physician were as follows:

March 6, 1929, white blood cells 5200, 16 per cent polymorphonuclears; May 25, 1929, white blood cells 1850, 22 per cent; May 27, 1929, white blood cells 2150, 8 per cent; May 28, 1929, white blood cells 2720, 28 per cent; May 29, 1929, white blood cells 4050, 52 per cent; June 3, 1929, white blood cells 6400, 64 per cent; June 13, 1929, white blood cells 3550,32 per cent; June 14, 1929. white blood cells 4000,40 per cent. 
Liver Extract (Lilly 343) was added in May to the treatment. On July 3, 1929, her white blood cell count was reported as 1400 and only 4 polymorphonuclears were seen in the entire smear. She died during a recurrence of her agranulocytic state according to a report from her family but they could give no details of her condition before death or her treatment. Nucleotide was not used in this attack as far as could be determined.

Patient $I I I .^{3}$ A nurse became acutely ill with sore throat. In her previous history it was noted that she had several attacks of tonsillitis. In April, 1926, an attack of tonsillitis was accompanied by a normal blood count. In November, 1927 , the hospital records show that an attack of tonsillitis was accompanied by a white blood cell count of 9400 but only 22 per cent polynuclears. In December, 1927 , she suffered from an attack of infectious mononucleosis having a blood count of 10,000 white blood cells, and 40 per cent polynuclears, 45 per cent small lymphocytes and 15 per cent large lymphocytes. In February 1929 she suffered from acute laryngitis with a normal white blood cell count and on three occasions 56, 60 , and 58 per cent polynuclears respectively. On June 6,1929 , she fell acutely ill with a sore throat. Table 3 summarizes the progress of her condition.

This patient developed on June 28th an infection in her left arm and had a fever for four days. After incision an uneventful recovery occurred. The response of the polynuclears during the complicating arm infection was evidently prompt and adequate and required no therapy beyond care of the local condition. During the course of her illness the following cultures were reported; the blood culture on the 26th of June was sterile; from her throat a gram + staphylococcus predominating with a few streptococcus, type not determined; from a well marked gingivitis, which developed, Vincent's spirilla; from her forearm lesion, a staphylococcus; and from a gangrenous area on her thigh, a streptococcus hemolyticus was cultured. A biopsy of this thigh lesion showed no polynuclears, only loose fibroareolar tissue with a few round cells. The patient has been perfectly well since her illness.

Two patients reported to have had agranulocytic angina were treated with nucleotide and died. One, a patient of Dr. Meyer A. Rabinowitz, Brooklyn, New York, was moribund when she received the first dose and died a few hours later. The other, a patient of Dr. Franklin M. Hanger, Presbyterian Hospital, New York City, died and the autopsy showed gangrene of the back of the throat and of the lungs. The details of these cases are not available.

Nucleotide therapy was tried in agranulocytosis accompanying infection. A patient of Dr. Davenport West, New York City de-

${ }^{3}$ I wish to thank Drs. E. J. Grace and E. P. Maynard, Jr. of the Brooklyn Hospital for their courtesy in permitting me to report this case. 
TABLE 3

Progress of Patient III treated during course of illness with nucleotide

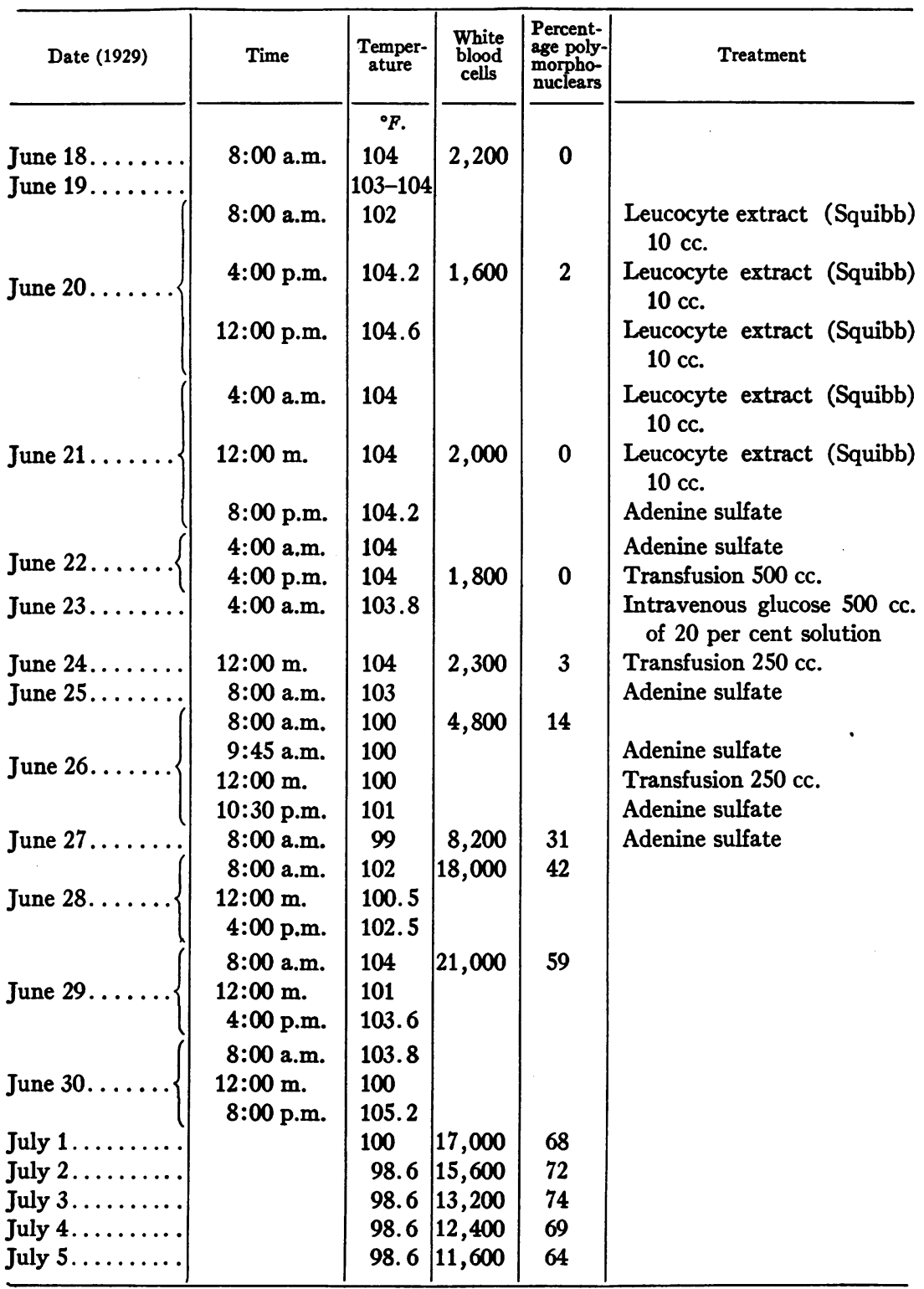


veloped a streptococcus hemolyticus septicemia. His blood culture plate showed about 200 colonies per cubic centimeter of blood. The details of his count are shown in table 4.

Dr. Hanger also had a patient with a staphylococcus infection of the face who did not respond to nucleotide treatment.

Six pneumonia patients showing marked leukopenia were treated with nucleotide. Marked increase in total and poly count were obtained in 5. However, 4 of these 5 died. In the case of 10 leukopenic pneumonia patients, who received no nucleotide, 4 showed

TABLE 4

Progress of Patient IV treated during course of illness with nucleotide

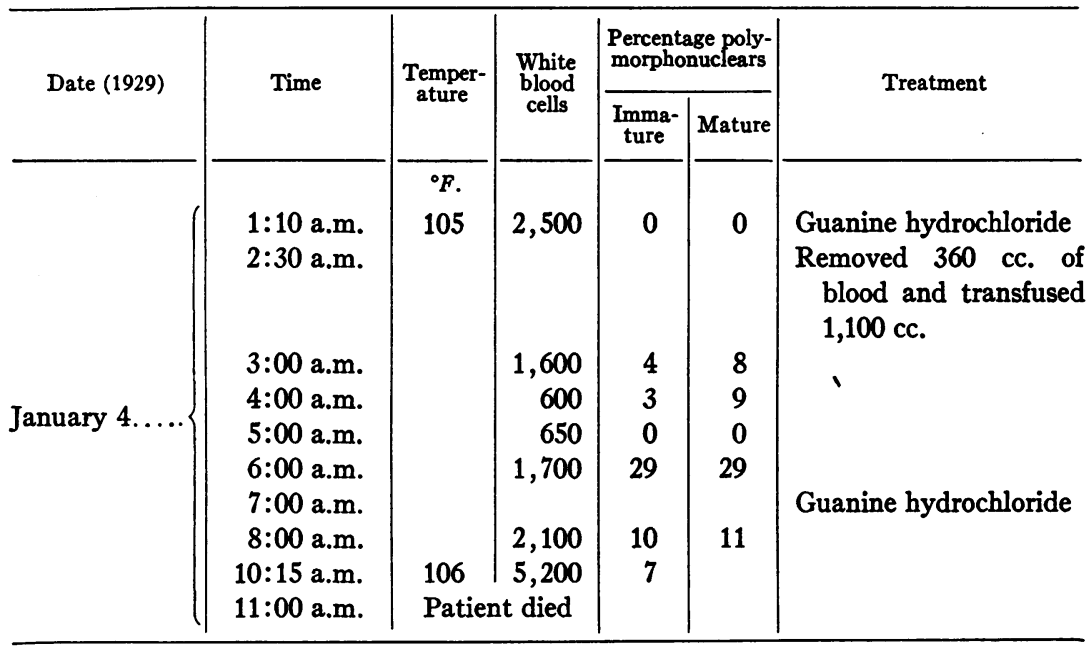

spontaneous increases in polynuclears and total count especially antemortem. The results of the use of nucleotide in pneumonia indicate that this is a profitable field for investigation. One of the possible deficiencies in the resistance of the pneumonic is a failure of cellular response as shown by a leukopenia. These patients are severely ill and most of them die. Therefore, it is probable that much larger and more frequent doses of nucleotide must be given than have been used in this work if a cellular response is to be elicited before the patient sinks too far. Moreover, in evaluating these results one must remember that there is a tendency for the bone marrow to pour forth young poly- 
morphonuclears just before death. This agonal rise should not be confused with nucleotide action. It seems probable, however, that nucleotide, pushed vigorously, can stimulate the bone marrow in pneumonia and its use may have an important place in the treatment of the disease when leukopenia is present.

The blood count of one agranulocytic patient with pulmonary tuberculosis gave no response to nucleotide therapy.

\section{COMMENTS}

The patients reported here do not represent the most desirable type of experimental material. They were extremely sick and every possibly helpful therapeutic measure was indicated. For example the 3 patients who recovered from agranulocytic angina received blood transfusions in addition to nucleotide. However, according to most authorities (1-14), the mortality rate in agranulocytic angina is just as high in patients who receive transfusions as in untreated patients. Moreover, the case of the patient who died from streptococcus hemolyticus septicemia illustrates that a transfusion, especially a large amount, markedly decreases the polymorphonuclear cells in the peripheral blood. If blood is to be transfused it should be given in small amounts, not over $250 \mathrm{cc}$. at a time, because of this depressing effect.

Friedemann (13) reports good results with $\mathrm{x}$-ray therapy. Six of ten patients recovered after such treatment, whereas only 2 of 24 untreated patients recovered previously in his series.

More complicated chemical products have been used for similar purposes, especially in pneumonia (25 and 26) and as long ago as 1897 Ames and Huntley (27) showed that nucleinic acid from yeast will increase the polymorphonuclear count. The demonstration of Buell and Perkins (28) that adenine occurs normally in the blood makes its use more rational than the more complex compound.

At present 0.5 gram of the nucleotide is given twice in 24 hours. Some response is seen within 6 hours after the injection and usually the increase in granulocytes is marked after the second dose.

\section{CONCLUSIONS}

1. Nucleotides given intravenously have the power of raising the peripheral polymorphonuclear count in certain agranulocytic conditions. 
2. Three patients, suffering from agranulocytic angina, recovered after intravenous injections of nucleotides during the course of their disease.

3. The use of nucleotides in agranulocytic angina seems to be a rational therapeutic measure.

\section{BIBLIOGRAPHY}

1. Hueper, W. C., Arch. Int. Med., 1928, xlii, 893. Agranulocytosis (Schultz) and the Agranulocytic Symptom Complex.

2. Allan W., Ann. Int. Med., 1928, ii, 542. Agranulocytic Angina with Thrombopenic Purpura.

3. Call, M., Gray, B. H. and Hodges, F. M., Am. J. Roentgenol., 1928, xx, 550. Agranulocytic Angina; Report of a Case with Recovery.

4. Trace, I. M., Ill. Med. J., 1929, lv, 36. Agranulocytic Angina.

5. Sharp, E. A. and Setterstrom, C. A., U. S. Naval Med. Bull., 1929, xxvii, 112. Agranulocytic Angina; Report of a Case.

6. Tynes, A. L., Virg. Med. Month., 1929, lv, 765. Agranulocytic Angina with Report of Case.

7. Reye, E., Med. Klin., 1929, xxv, 257. Zur Frage der Agranulocytose.

8. Potts, J. B., Arch. Otolaryng., 1929, ix, 256. Angina Agranulocytosis.

9. Bromberg, L. and Murphy, P., J. Am. Med. Assoc., 1929, xcii, 1266. Agranulocytic Angina Following Prophylactic Typhoid Vaccination.

10. Von Domarus, A., Klin. Wchnschr., 1929, viii, 779. Zur Lehre von der Agranulocytose.

11. Windham, R. E., Ann. Otol., Rhinol. and Laryngol., 1929, xxxviii, 470. Agranulocytic Angina; Report of Two Cases, One Death and One Recovery.

12. Hueber, W., Munch. Med. Wchnschr., 1929, lxxvi, 881. Beitrag zur Frage der Agranulozytose.

13. Friedemann, U., Ztschr. f. klin. Med., 1928, cviii, 54. Angina Agranulocytotica.

14. Stocké, A., Fol. Haematol., 1930, xl, 40. Beitrag zur Frage der Agranulozytose.

15. Schwarz, E., Mitt. d. Gesellsch. f. inn. Med. u. Kinderh., 1904, iii, 190. Ein Fall von extremer Leukopenie.

16. Schultz, W., Deutsche Med. Wchnschr., 1922, xlviii, 1495. Ueber eigenartige Halserkrankungen. (a) Monozytenangina.

17. Blumer, G., J. Am. Med. Assoc., 1929, xciii, 62. Occurrence of the Agranulocytic Blood Picture in Infections Other Than Angina.

18. Wilson, C. P., Am. J. Med. Sci., 1929, clxxvii, 88. Marked Monocytosis Accompanied by a Neutrophilic Leukopenia Following Antisyphilitic Treatment.

19. McCord, C. P., J. Am. Med. Assoc., 1929, xciii, 280. The Present Status of Benzene (Benzol) Poisoning. 
20. Roberts, S. R. and Kracke, R. R., J. Am. Med. Assoc., 1930, xcv, 780. Agranulocytosis. Report of a Case.

21. Reznikoff, P., J. Am. Med. Assoc., 1929, xciii, 963. Immature White Blood Cell Counts in Infectious Diseases.

22. Dameshek, W., J. Am. Med. Assoc., 1929, xciii, 712. Benzene Poisoning and Agranulocytosis.

23. Doan, C. A., Zerfas, L. G., Warren, S. and Ames, O., J. Exp. Med., 1928, lvii, 403. A study of the Mechanism of Nucleinate-induced Leucopenic and Leucocytic States, with Special Reference to the Relative Rôles of Liver, Spleen and Bone Marrow.

24. Reznikoff, P., J. Clin. Invest., 1928, vi, 16. Experimental Leukocytosis and Leukopenia.

25. Gardner-Medwin, F. M., Brit. Med. J., 1924, ii, 49. The Precipitation of Crisis in the Treatment of Pneumonia.

26. Miller, L. E., S. African Med. Rec., 1926, xxiv, 531. Treatment of Pneumonia Amongst Natives by Sodium Nucleinate.

27. Ames, D. and Huntley, A. A., J. Am. Med. Assoc. 1897, xxix, 472. The Nature of the Leucocytosis Produced by Nucleinic Acid; a Preliminary Experimental Study.

28. Buell, M. V. and Perkins, M. E., J. Biol. Chem. 1928, lxxvi, 95. Adenine Nucleotide Content of Blood with a Micro Analytical Method for Its Determination. 